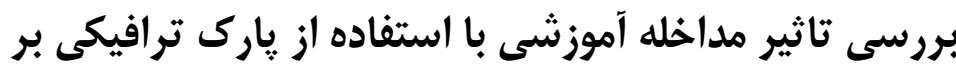

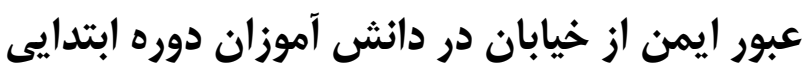

\author{
مرضيه توليده'، عباسعلى دهقان تفتى '، زهره رهايى'، سارا جام برسنگ'، حميد دهقان بنادكى
}

ا) كروه آموزشع بهداشت و ارتقاء سلامت، دانشكده بهداشت، دانشكاه علوم يزشكى شهيد صدوقى يزد، يزد، إيران

لم) كروه آمار زيستى، دلشكده بهداشت، دانشكاه علوم يزشكى شهيد صدوقى يزد، يزد، إيران

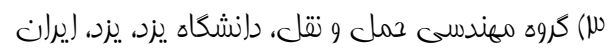

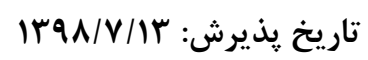

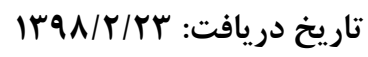

\begin{abstract}
جِكيده
مقدمه: عابرين يياده و به خصوص كودكان يكى از آسيب يذيرترين گروه هاى فعال در ترافيك را تشكيل مى دهند.

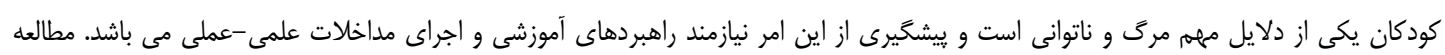

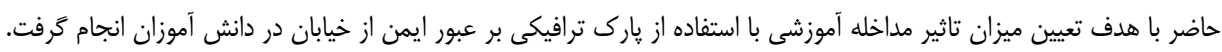

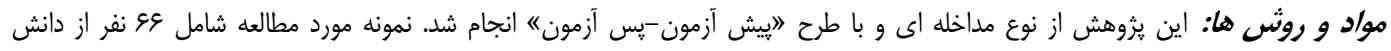

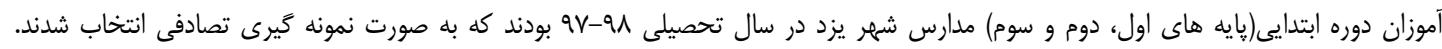

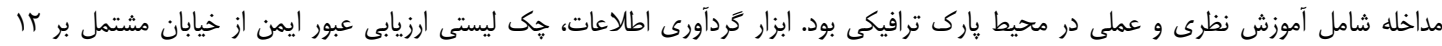

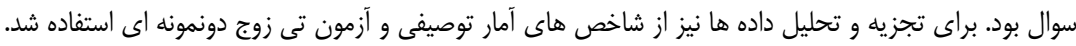

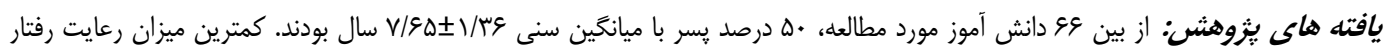

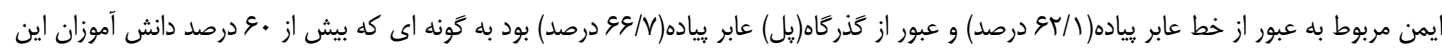

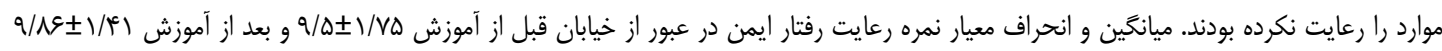

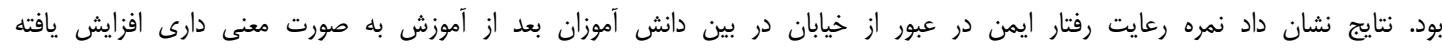

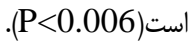

بحث و نتيجه كحيرىى: يافته ها نشان داد كه مداخله آموزشى با استفاده از يارك ترافيكى بر عبور ايمن از خيابان در دانش آموزان تاثير كذار بود

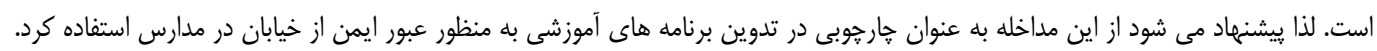

$$
\text { وازه هاى كليدى: عابرين پياده، يارك ترافيكى، دانش آموزان، عبور ايمن }
$$

* نويسنده مسئول: كروه آموزش بهداشت و ارتقاء سلامت، دانشكده بهداشت، دانشخاه علوم بزشكى شهيد صدوقى يزد، يزد، ايران Email:avintolide@yahoo.com

Copyright (C) 2019 Journal of Ilam University of Medical Science. This is an open-access article distributed under the terms of the Creative Commons Attribution international 4.0 International License (https://creativecommons.org/licenses/by-nc/4.0/) which permits copy and redistribute the material, in any medium or format, provided the original work is properly cited. 
به تابلوها و قراغ راهنمايى، تبليغـــــات ناكافى در زمينه هاى مختلف ايمنى عبور و مرور و هم هم هنين

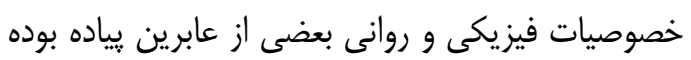
است(ه) (ه).

آسيب هاى عابرين يياده مشكلات زيادى از نظر

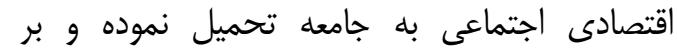

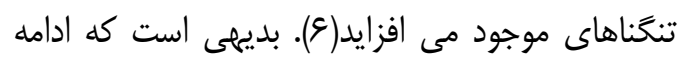

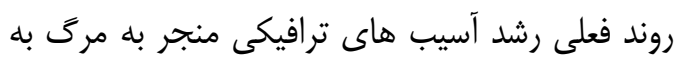

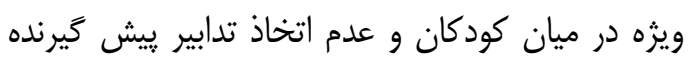
مناسب مى تواند به عنوان تهديدى بالقوه براى حيات

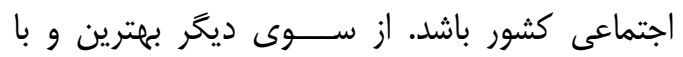

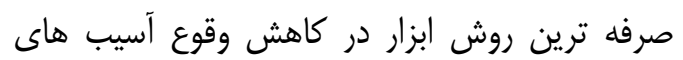
ترافيكى به كارگيرى راهكارها و برنامه هاى آموزشى و وني

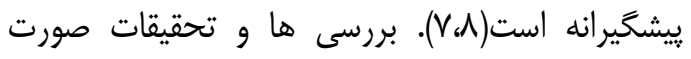

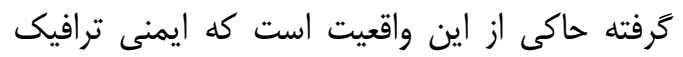

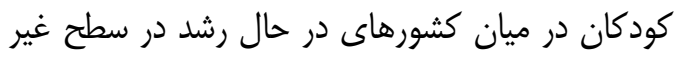

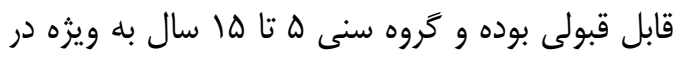

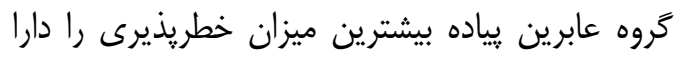

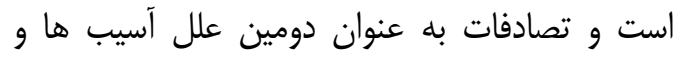

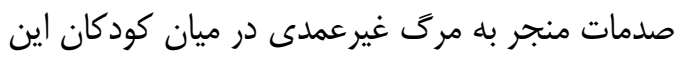

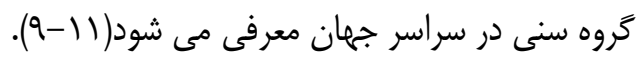

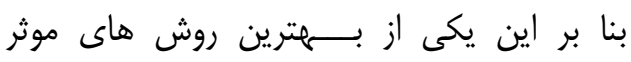

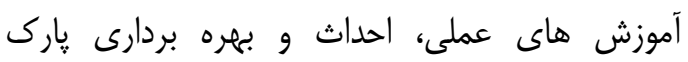

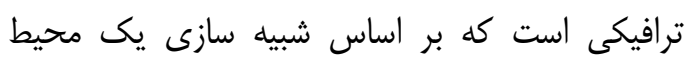

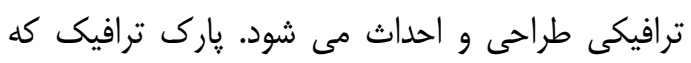

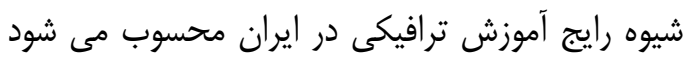
عبارت است از مجموعه آموزشى كه با شبيه سازى دي إنى محيط ترافيكى جهت آموزش هاى متنوع عملى إنى و

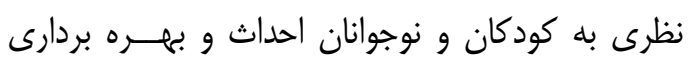

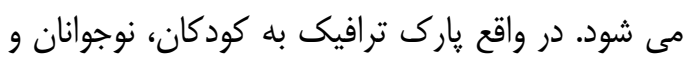

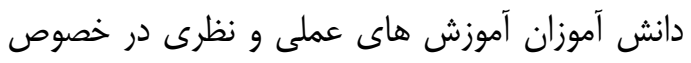

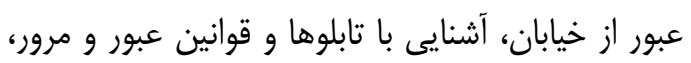

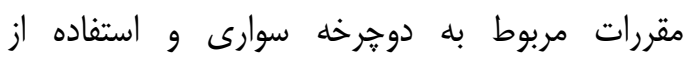

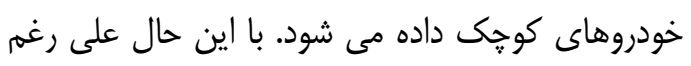
مطالعاتى كه به صورت مداخله ایى به بررسى تاثي داثير

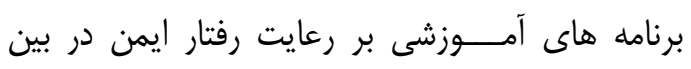

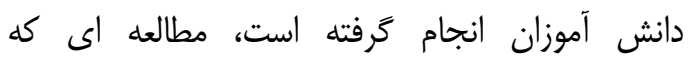

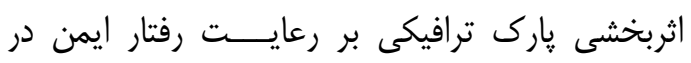

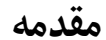

حوادث ترافيكى به عنوان سومين علت مرك و مير

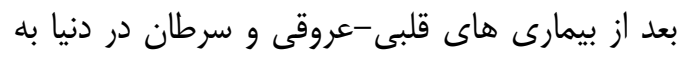

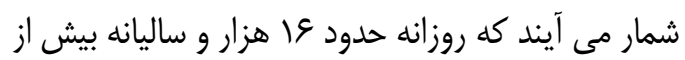

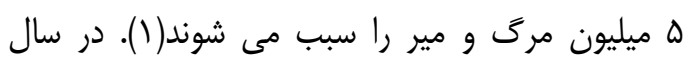

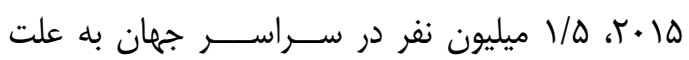

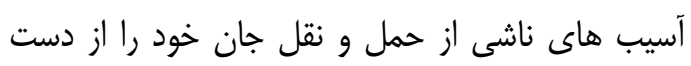

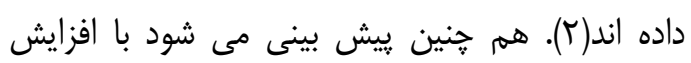

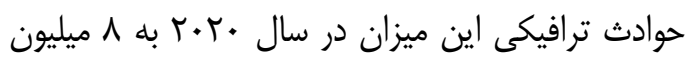

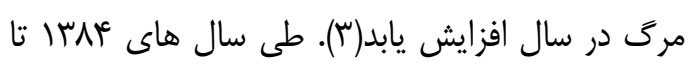

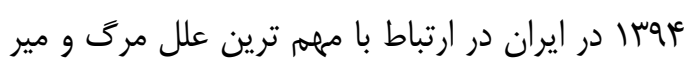

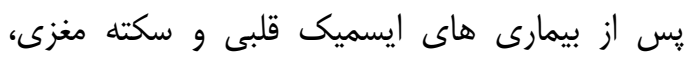

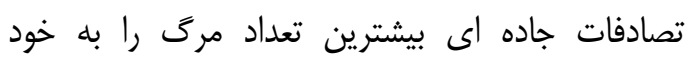

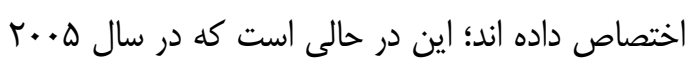

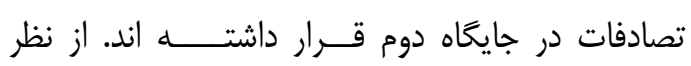

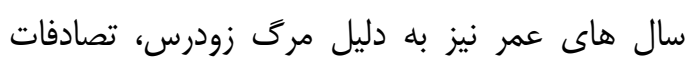

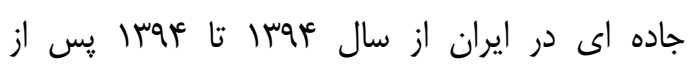

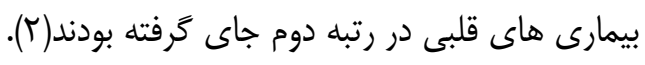

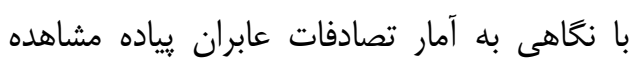

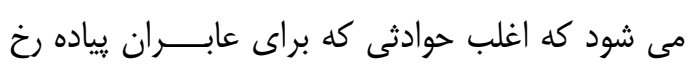

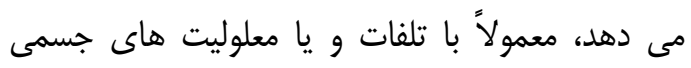

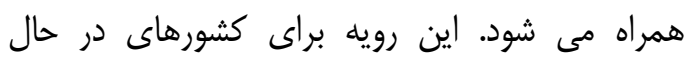

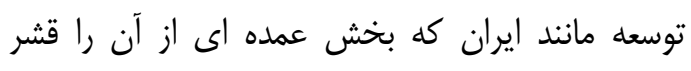

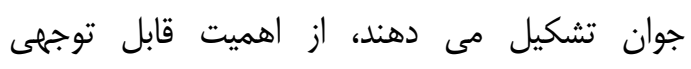

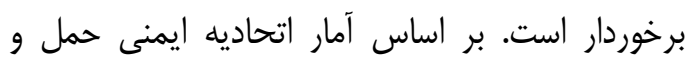

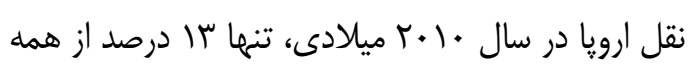

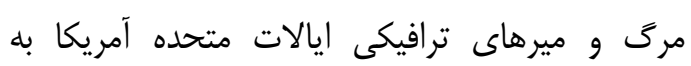

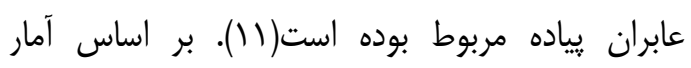

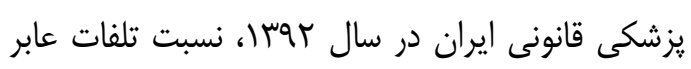

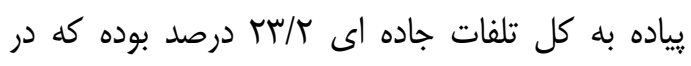

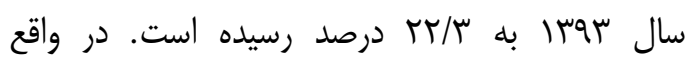

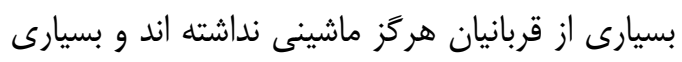

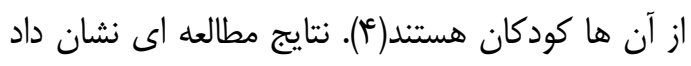
از باز درصد قربانيان آسيب هاى ترافيكى در ايران،

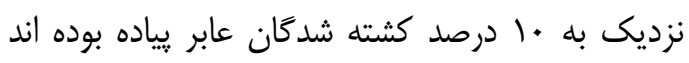

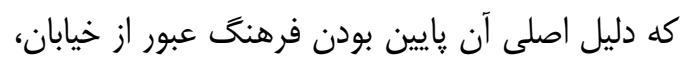

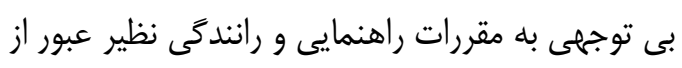
عرض خيابان و محل هاى خط كشى نشده، بى توجهى 


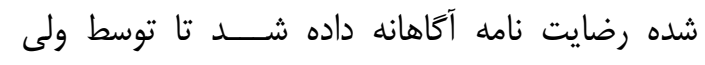

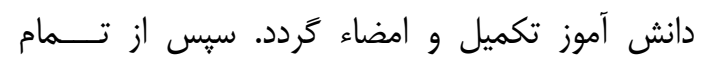

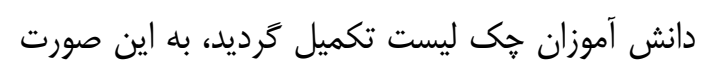
كه در فضاى يارى ترافيكى از دانش آموزان خوان خواسته

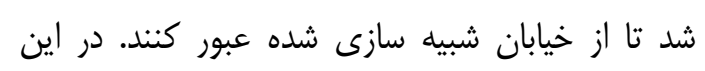

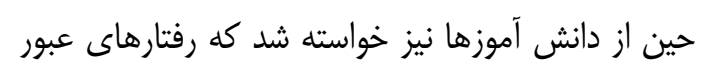

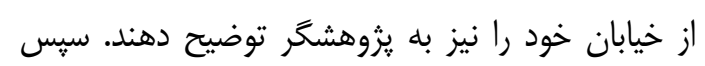

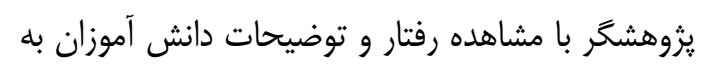
تكميل هی ليست مى برداخت. مداخله: آموزش كودكان در يارى ترافيكى توسط يليس در دو بخش نظرى و عملى صورت كرفت. بخش إنش

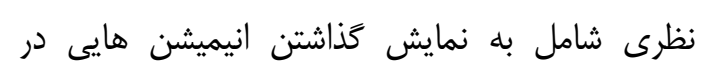

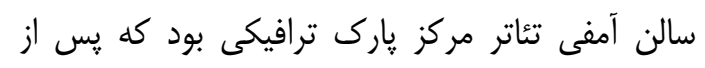

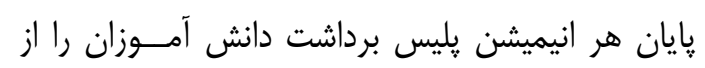

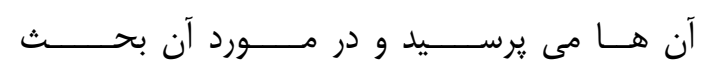
مصى كردند(محتواى انيميشن ها شامل آموزش نكاتى در در بحر خصوص بستن كمربند ايمنى توسط سرنشينان خودرو و و عبور از يل عابر يياده در خيابان بود).

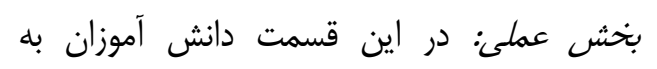

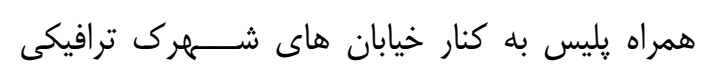
مى رفتند و يليس ضمن توضيح در خصوص خراغ

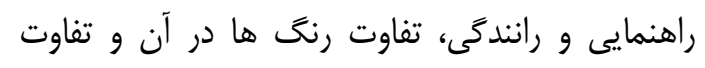

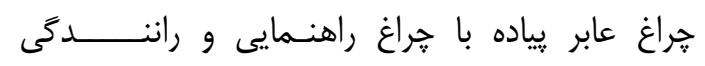

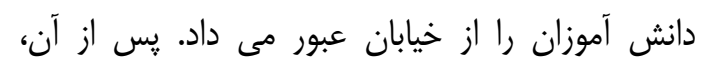

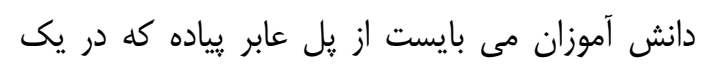

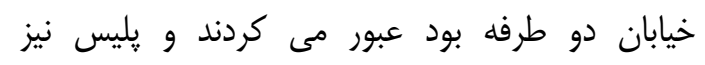

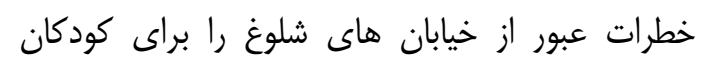

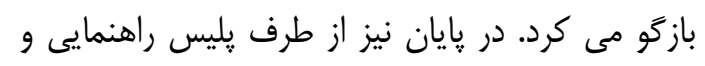

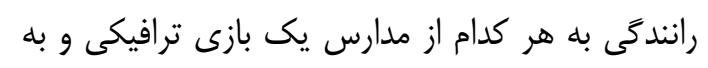

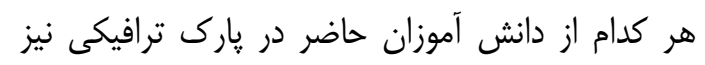

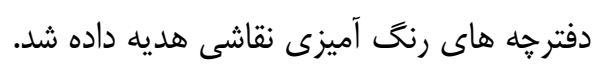

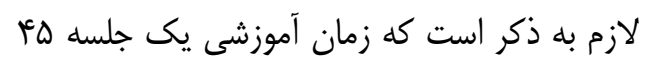

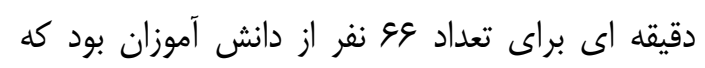
آموزش دهنده يك يليس راهنمايى و رانندى بعى بود.

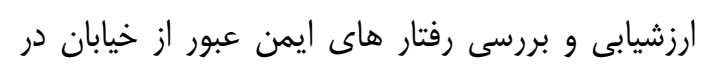

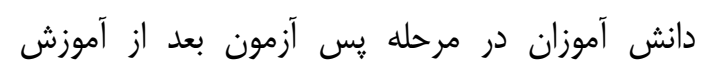

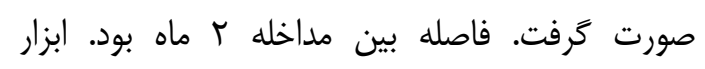

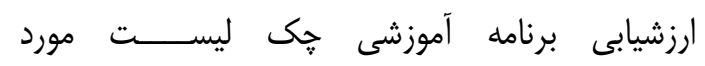

دانش آموزان را بررسى نموده باشد، مشاهده نشد. بر اين اساس مطالعه حاضر با هدف تعيين تاثير مداخله

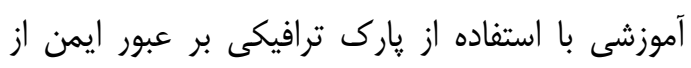
مواد و ورشان در دانش آموزان به انجام رسيد.

مطالعه حاضر از نوع مداخله اي بود. جامعه مورد

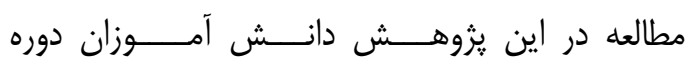

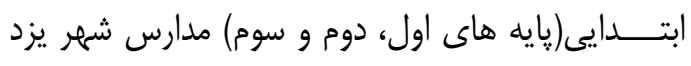
در سال تحصيلى Q1 يزوهش به صورت تصادفى بود. تعداد نمونه ها با باني

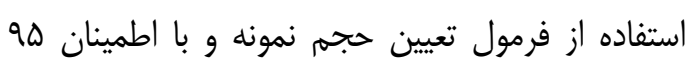

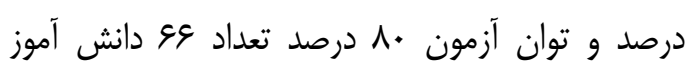

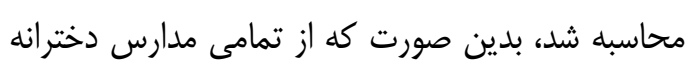

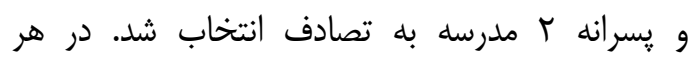

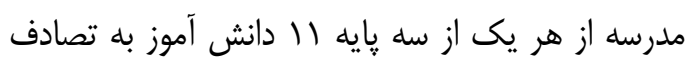

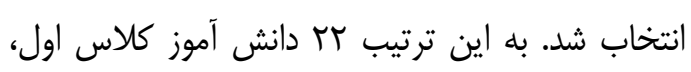

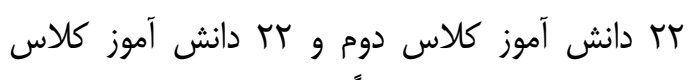

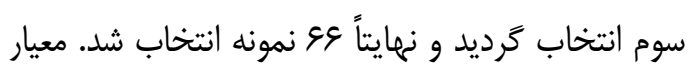

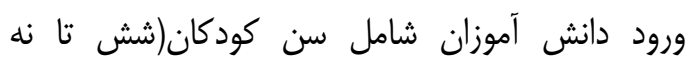

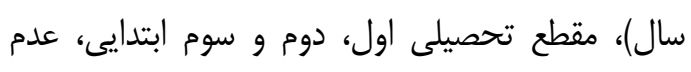

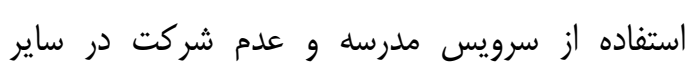

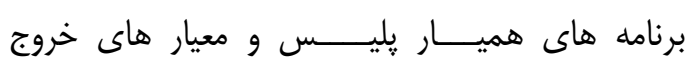
دانش آموزان عدم رضايت ولى دامئ دانش آموزان براى

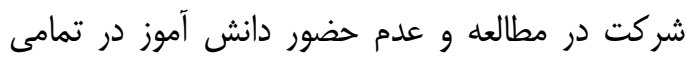
جلسات آموزشى بود. در اين يزوهش جهت سنجش رفتار عبور از خيابان

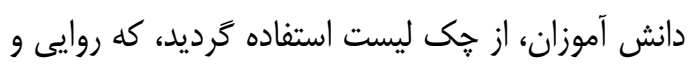

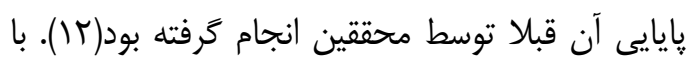

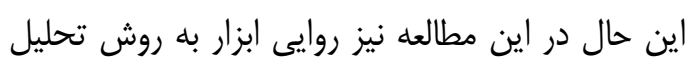

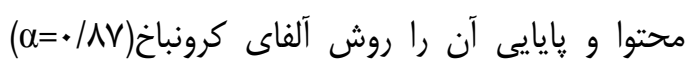

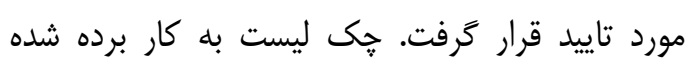
داراى ז' سوال بود كه هر كدام توسط محقق، يس از

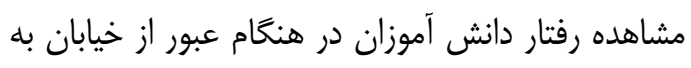

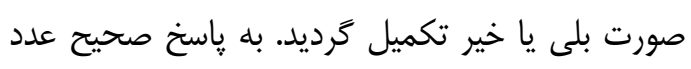

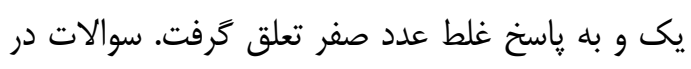
جدول شماره r ارائه شده است.

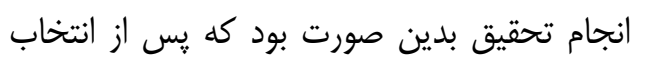

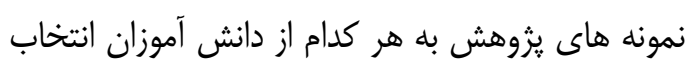


اطلاعات شخصى آن ها از جمله ملاحظات اخلاقى

$$
\text { مطالعه بود. }
$$

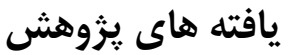

در مجموع ع 9 دانش آموز مورد مطالعه قرار كرفتند

كه •ه درصد دختر و •ه درصد يسر بودند. تحصيلات

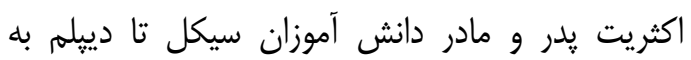
ترتيب با درصد هاى

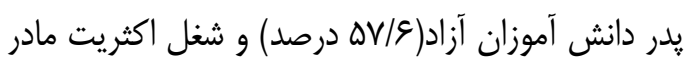
دانش آموزان خانه دار(q/\%ج درصد) بود(جدول شماره
اســــفاده در مرحله يِيش آزمون بود. پِ از انجام

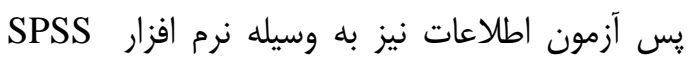

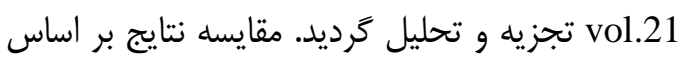

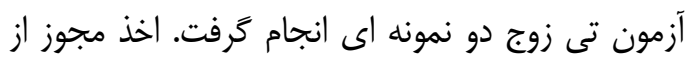

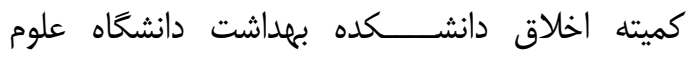

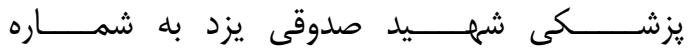

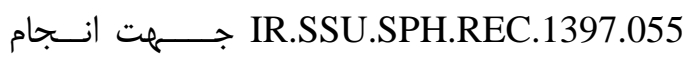
يروهش، اخذ رضايت نامه كتبى از والدين نمونه ها قبل

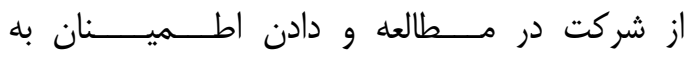
شركت كنندًان و والدين آن ها در مورد محرمانه بودن دان

\begin{tabular}{|c|c|c|c|}
\hline درصد & فراوانى & نوع & متغير \\
\hline Q. & Tr & دختر & \multirow{2}{*}{ جنسيت } \\
\hline$\Delta$. & 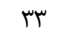 & پِّر & \\
\hline$T r / V$ & 10 & بى سواد تا ابتدايى & \multirow{3}{*}{ تحصيلات يدر } \\
\hline$V / r$ & ir & سيكل تا دييلم & \\
\hline $8 / 1$ & r & فوق دييلم و بالاتر & \\
\hline$r N / \Lambda$ & 19 & بى سواد تا ابتدايى & \multirow{3}{*}{ تحصيلات مادر } \\
\hline $9 T / 1$ & \&I & سيكل تا دييلم & \\
\hline $9 / 1$ & 9 & فوق دييلم و بالاتر & \\
\hline $9 / 1$ & 9 & كارمند & \multirow{3}{*}{ شغل يدر } \\
\hline & $\pi$ & كاركر & \\
\hline$\Delta V / \bar{q}$ & 山 & آزاد & \\
\hline · & · & كارمند & \multirow{3}{*}{ شغل مادر } \\
\hline $8 / 1$ & f & آزاد & \\
\hline $9 \% / 9$ & Gr & خانه دار & \\
\hline
\end{tabular}

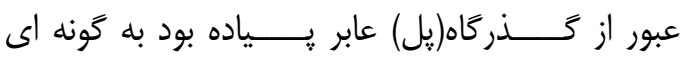

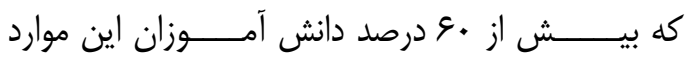

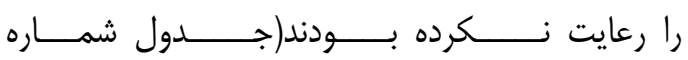
. $(\tau$
بر اساس نتايج در بين זا سوال مورد بررسى در

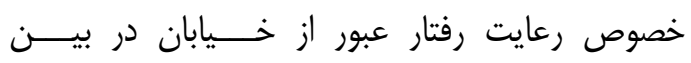

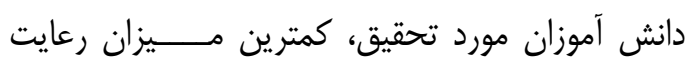

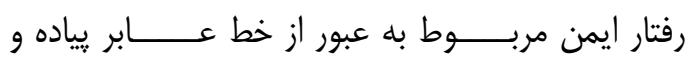

جدول شماره r. فراوانى و درصد نمرات دانش آموزان در وضعيت رفتار عبور از خيابان قبل و بعد از مداخله

\begin{tabular}{|c|c|c|c|c|c|c|}
\hline \multicolumn{6}{|c|}{ زمان } & \multirow{3}{*}{ 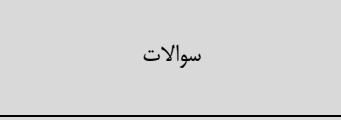 } \\
\hline \multicolumn{3}{|c|}{ بعد } & \multicolumn{3}{|c|}{ 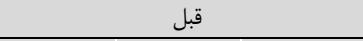 } & \\
\hline جمع نمرات & بله & خير & جمع نمرات & 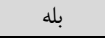 & خير & \\
\hline 99 & $(1 \cdot *) 98$ & $(\cdot) \cdot$ & 99 & $(1 \cdots) 98$ & $(\cdot) \cdot$ & ايستادن در كنار خيابان \\
\hline Q9 & $\left(\wedge q / \varphi^{c}\right) \Delta q$ & $(1 \cdot / 8) \mathrm{V}$ & $\Delta V$ & 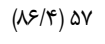 & $(1 \% / \varepsilon)^{q}$ & كوش دادن به صداى وسايل نقليه در خيابان \\
\hline st & $(9 \% / 9) \& 4$ & $(\xi / 1))^{f}$ & 84 & $(9 V) \& 4$ & $(r) r$ & نغاه كردن به سمت حֶب \\
\hline 9) & $(94 / 4) \& 1$ & $(V / \&) \Delta$ & gr & $(9 \% / 9) \& 4$ & $(\xi / 1))^{r}$ & نغاه كردن به سمت راست \\
\hline$\Delta 9$ & $(\wedge 9 / 4) \Delta 9$ & $(1 \cdot / 9) \vee$ & $\Delta V$ & 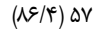 & $(1 r / 9)^{9}$ & نخاه دوباره به سمت حֶ \\
\hline$r \Delta$ & $(r V / Q) r_{\Delta}$ & $(q / /)+1$ & iv & $(T \Delta / \Lambda) \backslash V$ & $(V \in / T)+q$ & عبور از خط عابر يياده \\
\hline$\Delta S$ & $(\Lambda F / \Lambda) \Delta F$ & $(1 \Delta / r) 1$ & $\Delta r$ & $(V N / \Lambda) \Delta T$ & $(T / / T) \| F$ & ايستادن در وسط خيابان \\
\hline$\Delta F$ & $(\Lambda F / \Lambda) \Delta F$ & $(\mid \Delta / \Gamma) 1$. & $\Delta \Delta$ & 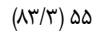 & $(19 / \mathrm{V}) 11$ & نغاه به سمت راست \\
\hline$\Delta S$ & $(\Lambda F / \Lambda) \Delta F$ & $(\mid \omega / \Gamma) 1$. & pq & $\left(V^{c} / T\right) \& q$ & $(T \Delta / \Lambda) I V$ & عبور از يياده رو \\
\hline rt & (Tr/T) & $(\varepsilon g / V)+q$ & rq & $(4 \Gamma / q) r q$ & $\left(\varepsilon_{\Delta} / \perp\right) \mathrm{rV}$ & عبور از كذركاه(يل)عابر يياده \\
\hline s & $(9 \Delta / \Delta) \& \mu$ & $(\tau / \Delta) \Gamma$ & $\Delta \mathcal{G}$ & $(\Lambda \tau / \Lambda) \Delta F$ & $(\mid Q / T) \mid \cdot$ & يرهيز از دويدن در خيابان \\
\hline 99 & $(1 \cdots) 98$ & $(\cdot) \cdot$ & $\boldsymbol{s}^{\mu}$ & $(9 \Delta, \Delta) \& \mu$ & $(r / \Delta) r$ & يرهيز از عبور مورب از عرض خيابان \\
\hline
\end{tabular}


نتايج نشان داد نمره رعايت رفتار ايمن در عبور از

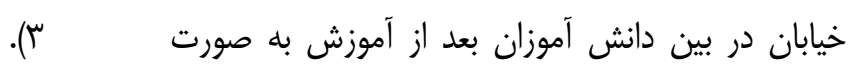

جدول شماره ب. مقايسه نمرات رعايت رفتار ايمن در عبور از خيابان قبل و بعد از مداخله

\begin{tabular}{|c|c|c|c|}
\hline سطح معنى دارى & اختلاف ميانكين & ميانكين و انحراف معيار & زمان \\
\hline \multirow{2}{*}{.$/ .99$} & \multirow{2}{*}{ צ צr/. } & $q / \Delta \pm 1 / \vee \Delta$ & قبل \\
\hline & & $q / N \notin \pm 1 / 4)$ & بعد \\
\hline
\end{tabular}

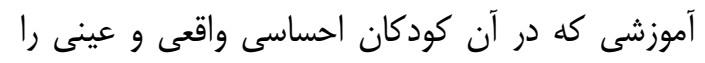

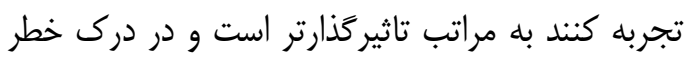

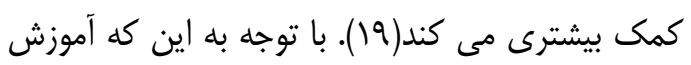

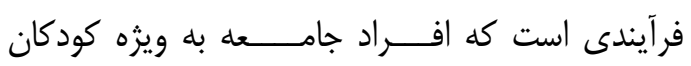
مى توانند از طريق آن نقش ها، انتظارات، قواعد و واند

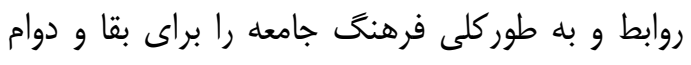

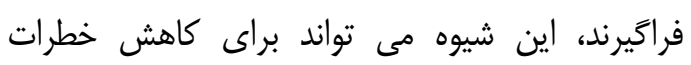
ترافيكى در كودكان و دانش آموزان موثر واقع گرددد.

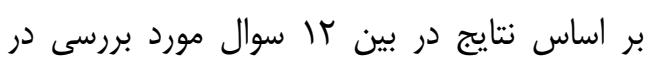

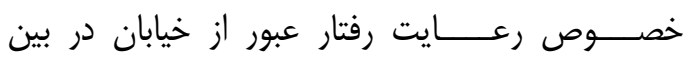

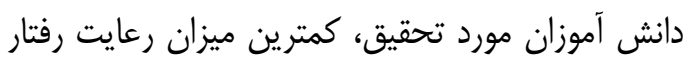
ايمن مربوط به عبور از خط عابر يياده و عبور از كذركاه

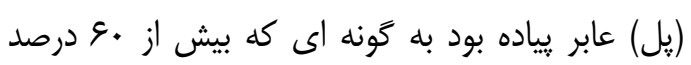

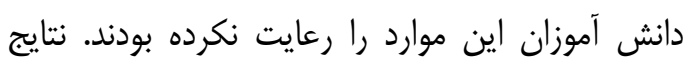

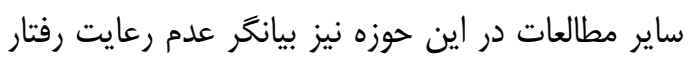

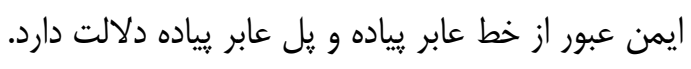

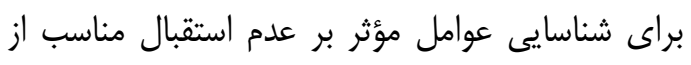

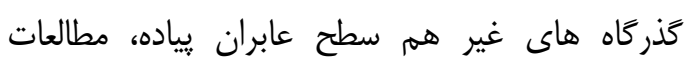

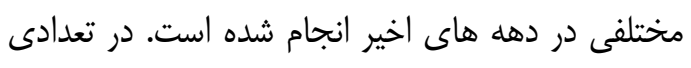

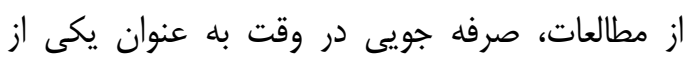

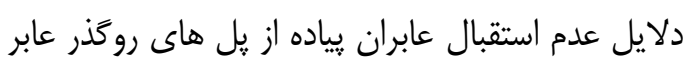

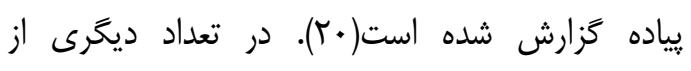

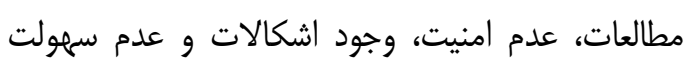

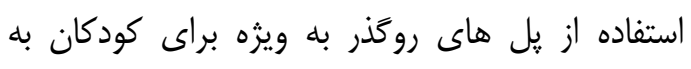

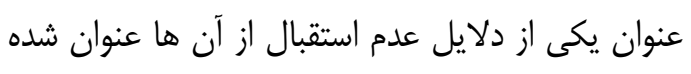

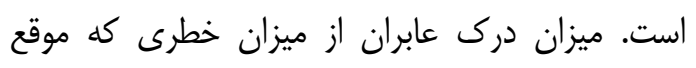

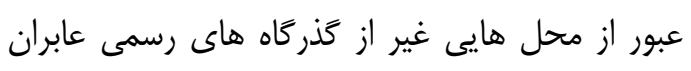

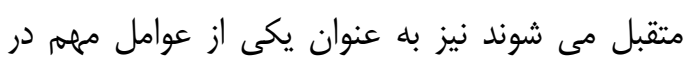

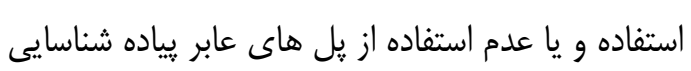

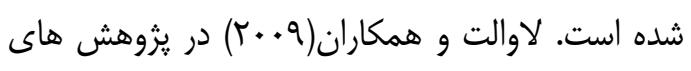
خود ززارش كردند كه اگر عابران يياده از تلفات

\section{بحث و نتيجه كَيرى}

نتايج يزوهش نشان داد ميانكين و انحراف معيار

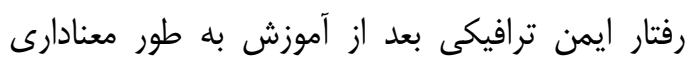

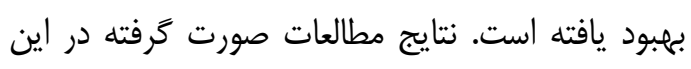

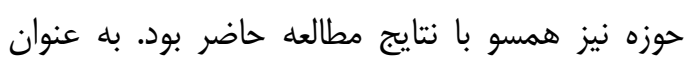

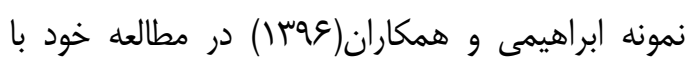
عنوان تدوين بسته آموزشى رفتار ترافيكى و تعيين

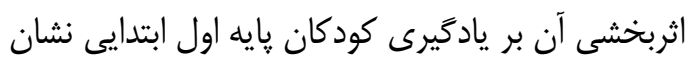

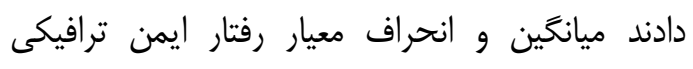

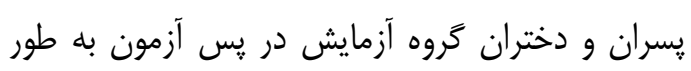

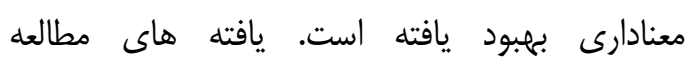

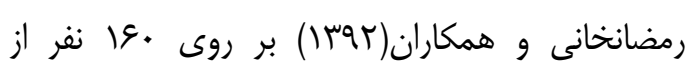
دانش آموز جهارم ابتدايى مدارس منطقه جهار تهان تهران

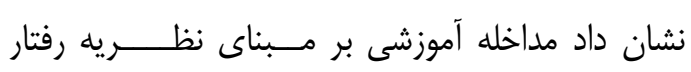

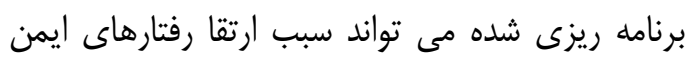

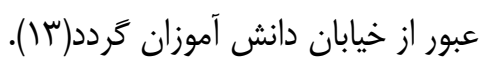
نتايج مطالعات انجام گرفتله در خارج از كشور نيز

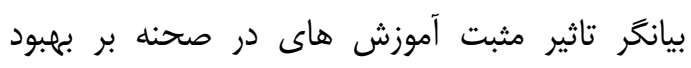
رفتارهاى ايمن در دانش آموزان است. بارت و همكاران

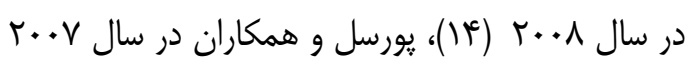

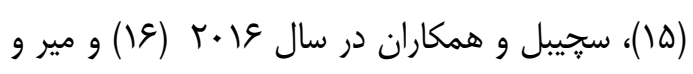

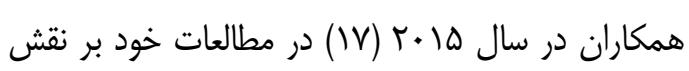

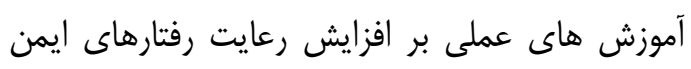

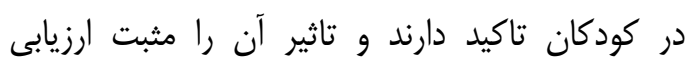

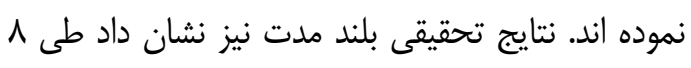

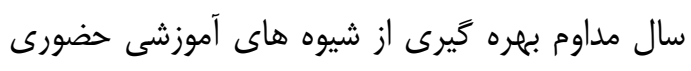

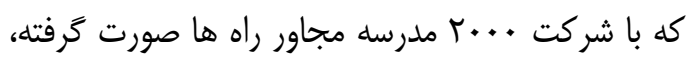
كاهش قابل ملاحظه اي در آمار تصادفات و تلفات

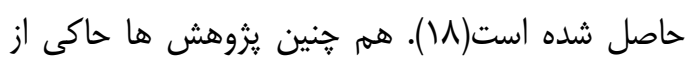

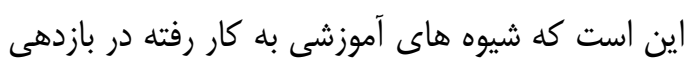

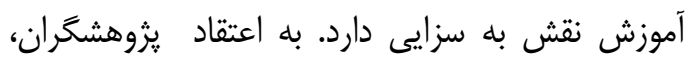




$$
\begin{aligned}
& \text { ييشنهاد مى شود از اين مداخله به عنوان جارجوبى در } \\
& \text { تدوين برنامه هاى آموزشى به منظور عبور ايمن ازئن ازئ }
\end{aligned}
$$

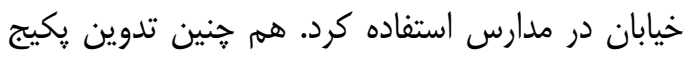

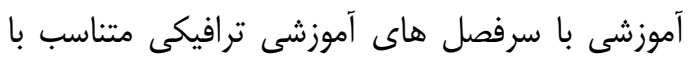

$$
\begin{aligned}
& \text { سن دانش آموزان، كنجاندن مولفه ها و سرفصل هاى ترى } \\
& \text { آموزشى ترافيـكى به عنوان فعاليت هاى يرورشى الهى } \\
& \text { دانش آموزان و آموزش اين مطالب توسط معلمان } \\
& \text { يرورشى و بهداشت ييشنهاد مى شود. براى انجام } \\
& \text { مطالعات آتى نيز ييشنهاد مى شود اين گَونه مطالعات } \\
& \text { در دانش آموزان ساير مقاطع و با طيف گسترده تر و با بئن } \\
& \text { الخوكيرى از كشور هاى بيشتاز در زمينه ترافيكى انجام }
\end{aligned}
$$

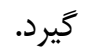

$$
\begin{aligned}
& \text { سباسگَزارى }
\end{aligned}
$$

اين مطالعه حاصل پايان نامه كارشناسى ارشد در

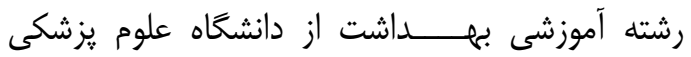

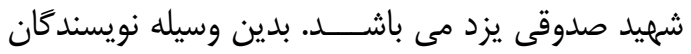

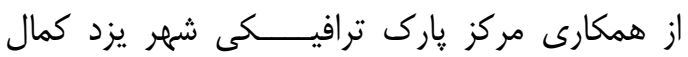

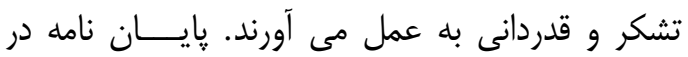

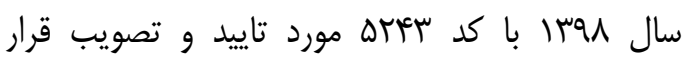

\section{References}

1.Chandran A, Hyder AA, Peekasa C. The global burden of unintentional injuries and an agenda for progress. Epidemiol rev 2010;32:110-20. doi: 10.1093/epirev/mxq009.

2.Wang H, Naghavi M, Allen C, Barber RM, Bhutta ZA, Carter A, et al. Global regional and national life expectancy all cause mortality and cause specific mortality for 249 causes of death 1980-2015 a systematic analysis for the global burden of disease study. lancet 2016;388:1459-544. doi: 10.1016/S0140-6736(16)31012-1.

3.Ansarimoghaddam A, Martiniuk AL, Mohammadi M, Rad M, Sargazi F, Sheykhzadeh K, et al. The pattern of injury and poisoning in South East Iran. BMC int Health Hum Right2012;12:17. doi: 10.1186/1472-698X-12-17.

4.Nantulya VM, Reich MR. The neglected epidemic: road traffic injuries in developing countries. BMJ 2002;324:1139-41. doi :10.1136/bmj.324.7346.1139
ترافيكى يا ديخر موارد مرتبط با ايمنى شخصى خود درك وسيعى داشته باشند، بر رفتار هُخونكى استفاده از جاده تاثير خواهد كذاشت. هم رجنين مطالعات رفتارى

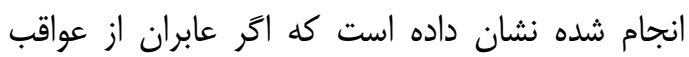

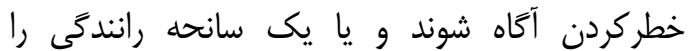
مشاهده يا تجربه نمايند، در هنكام عبور از خيابان بيشتر

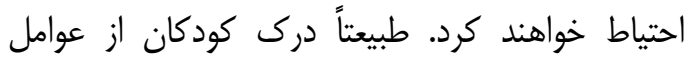
خطر نسبت به بزرگسالان كمتر بوده و لذاط تمايل

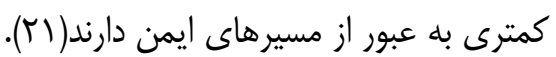

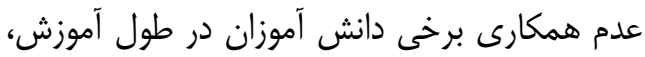
عبور از خيابان در مكان يارك ترافيكى، معطوف شدن

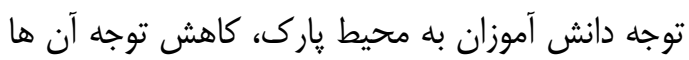

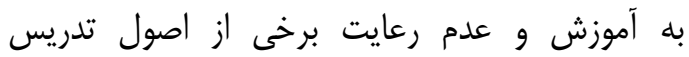

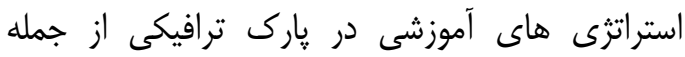

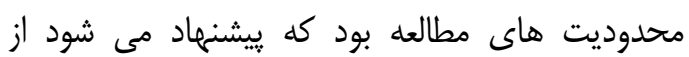
مدرسين مدارس استفاده كردد.

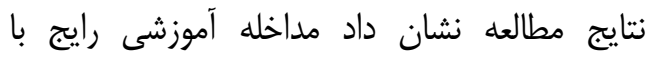
استفاده از پارك ترافيكى بر عبور ايمن از خيابان در دانش آموزان دوره اول ابتدايى موثر بوده و عبور ايمن إني

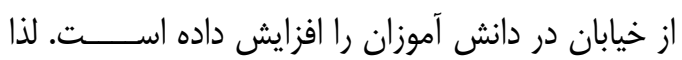

5.Mohammadfam A. [Traffic accidents and children threat against tomorrows]. J Pyam Farad 2007; 3: 29-23. (Persian)

6.Bayray A, Cherie A. Assessment of road traffic accidents among children in Addis ababa city Ethiopia a retrospective record review. Res Rev J Med Sci Technol 2019;3:25-36.

7.Holakoee K, Moradi A. [Knowledge attitude and performance pedestrians on traffic regulations in the area through the main intersection in Tehran]. Payesh J2007; 6: 35-37. (Persian)

8.Gupta M. Safety and security concerns for primary school children. Home Sc 2019;2:1-8.

9.Zhuang $\mathrm{X}$, Wu C. Pedestrians crossing behaviors and safety at unmarked roadway in China. Acc Ana Preve2011;43:1927-36. doi: 10.1016/j.aap.2011.05.005

10.Inada $\mathrm{H}$, Tomio $\mathrm{J}$, Ichikawa $\mathrm{M}$, Nakahara S. Regional disparities in road traffic injury rates involving elementary and junior high school children while 
commuting among Japans 47 prefectures between 2004 and 2013. Acc Ana Preve 2019;125:79-84.

doi : 10.1016/j.aap.2019.01.028

11.Anjuman T, Hasanat S, Siddiqui CKA, Hoque MM. editors. Road traffic accident a leading cause of the global burden of public health injuries and fatalities. Proc Int Con Mech Eng Dhaka Bangladesh 2020;2:12309.

12.Zare H. [Effect of parental involvement in children education for safe street crossing skills]. Tarbiat Modares Uni J2017;4:32-09. (Persian) doi: 10.1016/j.trf.2018.10.021

13.Ramezankhani A, Khalafenilsaz M, Dehdari T, Soori H, Tavasoli E, Khezli M. Effects of an educational intervention based on planned behavior theory in promoting safe behaviors crossing the street in students. J Health Syst Res2014;1:2000-10. 14.Bart O, Katz N, Weiss PL, Josman N. Street crossing by typically developed children in real and virtual environments. Occup Part Health 2008;28:89-96. doi: 10.3928/15394492-20080301-01

15.Purcell C, Wilmut K, Wann JP. The use of visually guided behaviour in children with developmental coordination disorder when crossing a virtual road. Hum Move Sci 2017;53:37-44. doi: 10.1016/j.humov.2016.11.007

16.Schwebel DC, Shen J, McClure LA. How do children learn to cross the street? Traff Injur Preve2016;17:573-9.

doi: 10.1080/15389588.2015.1125478

17. Meir A, Orongilad T, Parmet Y. Are child pedestrians able to identify hazardous traffic situations? Safe Sci 2015;80:3340.doi: 10.1016/j.ssci.2015.07.007.

18.Lerner JS, Keltner D. Fear anger and risk. J Personal social Psychol 2001;81:146. doi: 10.1037/0022-3514.81.1.146

19.Zeedyk MS, Kelly L. Behavioural observations of adult child pairs at pedestrian crossings. Acc Ana Preve2003;35:771-6. doi: 10.1016/S00014575(02)00086-6

20.Pasha MM, Rifaat SM, Hasnat A, Rahman I. Pedestrians behaviour on road crossing facilities. Jurnal Teknol 2015;73:41-06.

21.Lavalette BC, Tijus C, Poitrenaud S, Leproux C, Bergeron J, Thouez J-P. Pedestrian crossing decision-making: A situational and behavioral approach. Safe Sci 2009;47:1248-53. doi: 10.1016/j.ssci.2009.03.016 


\title{
Effect of Educational Intervention Using Children's Traffic Park on Safe Crossing from the Street among School Children
}

\author{
Tolide $M^{1}$, Dehghanitaftiti $S^{1 *}$, Rahaei $Z^{1}$, Jambarsang $S^{2}$, dehghanbanadaki $H^{3}$
}

(Received: May 13, 2019

\begin{abstract}
Introduction: Pedestrians, especially children, are among the most vulnerable active groups in traffic. One of the major causes of death and disability is pedestrian and children injuries. Therefore, it is important to prevent these injuries, which requires educational strategies and implementation of scientific-practical interventions. This study aimed to investigate the effect of educational intervention on safe crossing along the street among students using Children's Traffic Park in Yazd, Iran.
\end{abstract}

Materials \& Methods: This interventional study was conducted with a pretest-posttest design. This study included 66 elementary students $\left(1^{\text {st }}, 2^{\text {nd }}\right.$, and $3^{\text {rd }}$ grades $)$ who were selected by random sampling from schools in Yazd, Iran, during the academic year of 2018-19. The intervention consisted of theoretical and practical training in the Children's Traffic Park. The data were collected using a 12-item checklist assessing the safe crossing of the street. Moreover, the data were analyzed through descriptive statistics and a paired twosample Student's t-Test. Ethics code: IR.SSU.SPH.REC.1397.055
Accepted: October 5, 2019)

Findings: In total, $50 \%$ of the students were male with a mean age of $7.65 \pm 1.36$ years. The minimum level of respecting safe behaviors was related to passing through the crosswalks (62.1\%) and pedestrian overpasses $(66.7 \%)$. Therefore, it was revealed that more than $60 \%$ of the students did not comply with these safety behaviors. The mean $\pm \mathrm{SD}$ scores of respecting safe behaviors when crossing the street were $9.5 \pm 1.75$ and $9.86 \pm 1.41$ before and after the intervention, respectively. The results also showed a significant increase in the scores of respecting safe behavior when crossing the street among students after the intervention $(\mathrm{P}<0.006)$.

Discussion \& Conclusions: According to the obtained results, educational intervention using children's traffic park had effects on the safe crossing of the students from the street. Therefore, it is suggested that this intervention be implemented as a framework for developing educational programs to train schoolchildren regarding crossing the street safely.

Keywords: Children's Traffic Park, Pedestrians, Safe Crossing, Students

1. Dept of Health Education, Faculty of Health, Yazd Shahid Sadoughi University of Medical Sciences, Yazd, Iran

2. Dept of Biostatistics, Faculty of Health, Yazd Shahid Sadoughi University of Medical Sciences, Yazd, Iran

3. Dept of Transportation Engineering, Faculty of Engineering, University of Yazd, Yazd, Iran 